\title{
SECONDARY AMYLOID INFILTRATION AROUND THE LIMBUS*
}

\author{
BY \\ M. L. BEHAL \\ Military Hospital, Jabalpur, India
}

THERE are many reports in the literature of secondary amyloid infiltration of the eye and adnexa, which seems to be common in the tarsus and bulbar conjunctiva (Redi, 1948; Chinaglia, 1952; Agarwal and Shrivastav, 1958; Mathur and Mathur, 1959; Hameed and Nath, 1960; Richlin and Kuwabara, 1962).

An unusual case of amyloid infiltration around the limbus of both eyes is reported below.

\section{Case Report}

A female aged 25 years was admitted to hospital with a fleshy mass in the left eye of 7 years' duration. She had suffered from congestion and watering of both eyes for many years.

\section{Examination}

Left Eye: Visual acuity 6/12; pupil active; fundus and visual fields normal; tarsus of upper lid fibrosed with pannus, because of chronic trachoma. A fleshy mass encircled the cornea; it was attached to the limbus and the conjunctiva could be moved over it (Fig. 1).

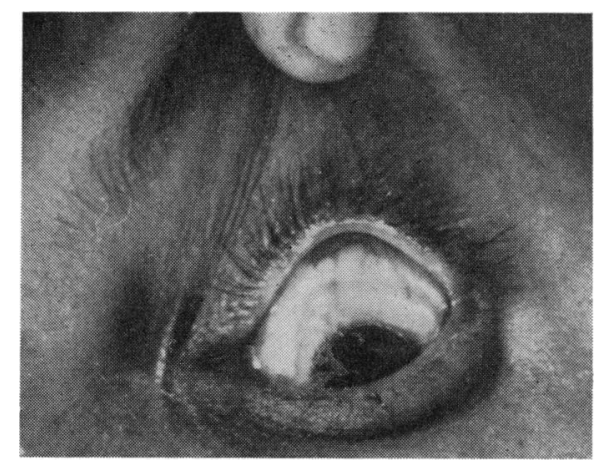

FIG. 1.-Left eye, showing a fleshy mass extending around the cornea and over the limbus.

The slit lamp showed that the superficial layers of the fleshy mass were transparent and appeared to be piled up layer upon layer, with blood vessels piercing into the mass at many points (Fig. 2 opposite). The left pre-auricular lymph gland was not enlarged.

Right Eye: Visual acuity 6/60; pupil active; fundus and visual fields normal; tarsus of upper lid fibrosed; pannus and nebula over the cornea were due to chronic trachoma. Under the loupe the limbus appeared to be normal, but the slit lamp showed fine "cotton wool" fibres arranged layer upon layer with blood vessels passing into them.

General Condition.-Normal; liver and spleen not enlarged. 

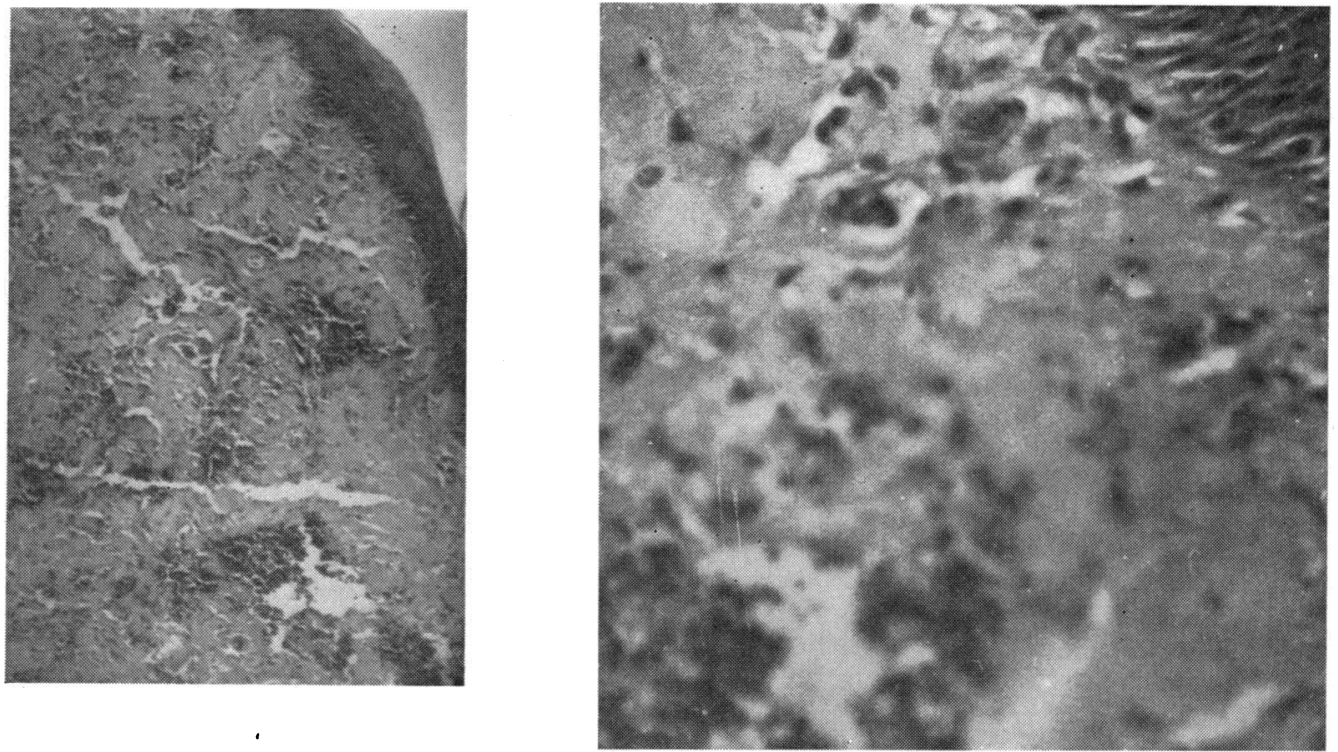

FIG. 2.-Photomicrographs of sub-epithelial amyloid infiltration. $\quad \times 200$.

Laboratory Investigations.-Blood Wassermann reaction and Kahn test negative. Total white blood corpuscles 8,000 per c.mm., polymorphs 70 , lymphocytes 29 , eosinophils 1 . No abnormal leucocytes detected. Urine analysis normal. Lung and skull $x$ rays normal.

Diagnosis.-Chronic trachoma with secondary amyloid infiltration around the limbus.

\section{Discussion}

The mechanism of amyloid infiltration is still not clear. In a large number of cases it follows or co-exists with chronic trachoma (Duke-Elder, 1962). Considering the high incidence of trachoma in India the reports of amyloid infiltration in the literature are few, and in most cases there was involvement of one eye only. There may be a long interval before the second eye is visibly involved, and an early slitlamp examination is necessary to prove the bilateral pathology. In this case the limbal and perilimbal areas were infiltrated in both eyes.

\section{Summary}

A case is reported of amyloid infiltration around the limbus secondary to chronic trachoma and the slit-lamp appearances are described.

I thank Lt.-Col. C. S. Singh, O.C. Military Hospital, Jabalpur, for permitting me to report this case, and Maj. E. Balakrishnan for his assistance.

\section{REFERENCES}

Agarwal, S., and Shrivastav, J. B. (1958). Brit. J. Ophthal., 42, 433.

Chinaglia, V. (1952). Ann. Ottal., 78, 81 .

DUKE-ElDER, S. (1962). "System of Ophthalmology", vol. 7. Kimpton, London.

HAMEed, S., and NATH, K. (1960). Amer. J. Ophthal., 49, 814.

Mathur, S. P., and Mathur, B. P. (1959). Brit. J. Ophthal., 43, 765.

REDI, F. (1948). G. ital. Oftal., 1, 227.

Richlin, J. J., and Kuwabara, T. (1962). Arch. Ophthal., 67, 138. 